\title{
TRADICIÓN Y MODERNIDAD DE LAS CIENCIAS FÓNICAS: FONÉTICA Y FONOLOGÍA
}

La historia del examen del fenómeno fónico, el de la voz humana, se remonta aproximadamente setenta siglos atrás.

Desde tiempos remotísimos (antiguas civilizaciones hindú, egipcia y polinesia) el hombre comenzó a reflexionar sobre la procedencia fisiológica del fenómeno sonoro corpóreo, su naturaleza y origen mismo en las interioridades anatómicas del hablante. Podría decirse, que así se inauguran las ciencias fónicas, la fonética, particularmente. Posteriormente (en las culturas clásicas griega e hindú), notables pensadores que mencionaremos luego, comenzaron a reflexionar ahora sobre el valor, función, oficio, combinación y posición de los sonidos dentro de la cadena fónica: surgen entonces, los primeros intentos fonológicos en la intuición de los pensadores helénicos.

Aunque desde los comienzos de la aparición de estas dos disciplinas, como maneras diferentes de apreciar el sonido, y hasta bien entrado el siglo XX, estuvieron ellas un tanto distanciadas, especialmente por voluntad de fonólogos, están ellas hoy feliz e indispensablemente unidas, como debe ser, pues el motivo de su estudio, el sonido de la voz humana, es el mismo, aunque desde diferentes ángulos; es así coma ya hoy no se justificaría divorcio alguno entre ellas, si bien estudian el sonido desde diferentes ópticas. En resumen, toda escisión entre fonietistas y fonólogos resultaría modernamente injustificable.

La fonética es una ciencia natural y tiene que ver con las otras disciplinas básicas humanas, a excepción tal vez de la geología como lo dijera con mucho acierto el fonólogo inglés, Daniel Jones. Y de verdad que existe alguna relación, en mayor o menor escala, de la fonética con todas las ciencias mayores. En sus campos específicos, ella se remite al conocimiento del sonido en sus cuatro componentes, acústicos (tono, timbre, intensidad y duración). La fisiofonética, como la denominara Baudouin de Courtenay, estudia la intensidad y volumen de los sonidos y su clasificación en tensos y débiles, analiza la agudeza o gravedad de su frecuencia, estima su duración en larga o breve, su compacticidad o difusión, su estridencia o maticidad; de la realización fónica humana, examina su labialidad, su velaridad, su coronalidad, su palatalidad, su apicalidad, su dentalidad, su alveolaridad, su faringalidad, su constitución vocálica o consonántica, su sonoridad o su sordez, su nasalidad, su oralidad, su glotalidad, su rechinación, su musitación; y como toda lengua es musical (tonal o entonativa), de ello deduce sus tesituras bemoles o sostenidas, entre otros muchos aspectos; a partir del panorama anterior, entran los sonidos a ser clasificados, posteriormente, en una taxonomía fonética-fonológica de haces o matrices y en diferentes concepciones, según las distintas escuelas fonológicas. 
Son también tareas fonéticas la medición de los sonidos en hertzios, decibeles y diezmilisegundos, o la estimación impresionística de los mismos, con propósitos descriptivos o utilitaristas; determinados ellos por su mayor o menor magnitud, en la cadena fónica, procede luego el examen de su relevancia con propósitos significativos a nivel psico-fonético (fonológico) en determinadas lenguas. De esta forma, éstas se denominarán cuantitativas o intensivas, o dinamicas, o tonales, o cualitativas o cromáticas, si correspondientemente la duración, el acento prosódico, el tono o el timbre cobran valor significativo. Son intereses igualmente fonéticos, la descripción auditiva, visual que se haga de la modalidad fónica de determinada lengua; estas modalidades específicas constituyen la base articulatoria $o$ particularidades fonoarticulatorias y acústicas, que son, en definitiva, la tipificación de un idioma en especial; también son fonéticos estos aspectos: los estimativos de la capacidad de audición frecuencial de las personas $(16-16.384 \mathrm{~Hz}$.), su capacidad auditiva por intensidad (14-140 decibeles); la clasificación de los sonidos en ultrasónicos, infrasónicos, inaudibles, soportables o nocivos; el examen de las modificaciones que cada sonido sufre en la cadena por acción de los fonos vecinos (fonética combinatoria), y hasta la connotación, a un nivel un tanto abstracto, que los ruidos de la naturaleza tengan en la creación poética, por la presencia o reiteración en lo escrito, de ciertos fonemas. Esta relación de los sonidos con el sentido, se denomina estilística fonética; son también ramas o campos de la fonética: la utilización de los recursos sonoros de la voz en el arte dramático, en el teatro, en la radio, en la televisión, en el canto, en la declamación, en la oratoria, en la ópera, del examen de los desajustes, trastornos y retardos de lenguaje en los tartamudos, sordos, mudos o enfermos o afectados por diferentes afasias (fonética aplicada al campo foniátrico, terapéutico $u$ ortofónico en lo normativo, clínico o quirúrgico); y hasta el descubrir que la expresión fónica de las personas en algunas lenguas, caracterizadas éstas unilateralmente por peculiaridades fonéticas, identifica el sexo, su procedencia geográfica, su estado anímico, como lo describiera y aseverara Trubetzkoy, es también otra rama fonética, denominada fonoestilística.

¿Y los constituyentes de la fonología? Se aplica esta otra vertiente al descubrimiento del número de sonidos significativos de una lengua (fonemas); sus reglas de combinación, su oficio, su relación con la significación (básica para la semántica) por la presencia funcional de pares mínimos como porte/poste, moral/morral, fardo/dardo (oposiciones fonológicas), su distribución inicial, medial o final en el lexema (divinidad), su número finito en cada lengua: ( 25 en español, 38 en inglés, 33 en francés, 35 en alemán, 34 en italiano) y el servicio que tales unidades prestan para distinguir textos o construir mensajes tales como contesto para aclarar/contexto para aclarar. De gran funcionalidad son, pues, los oficios fonológicos.

Pero lo más importante de toda esta disquisición es que nos servimos, inconscientemente, tanto de la una como de la otra, con útiles propósitos y una definida finalidad: la comunicación humana, base e instrumento de la convivencia universal. Estas dos hermosas ramas de la ciencia han movido a la sociedad desde los tiempos de la caverna y la seguirán moviendo, así el mundo invente los más sofisticados instrumentos científicos en la tecnología de la comunicación; el alma del hombre es el lenguaje, icómo no!, pues el hombre como animal que habla, se distingue por poseer un alto y complejo sistema de comunicación, como ningún otro ser viviente; sin este instrumento lingüístico, el universo sería una colectividad vacía, casi estática; gracias a él, se han hecho y planeado significativos 
descubrimientos, avances, tratados, pactos de paz, libros, discursos, todo, fruto de la comunicación y del lenguaje articulado, constituido éste por simples fonemas y alófonos, y cuyas cifras pueden variar en cada lengua de acuerdo con los criterios de clasificación de las distintas escuelas fonológicas y sus respectivos tratadistas, y las diversas modalidades de pronunciación individual, regional, dialectal u ocasional.

\section{Tradición histórica}

Como anotábamos al comienzo, son variadas las circunstancias de esta tradición histórica. Veámoslas: el hallazgo y la existencia de gráficos micronesios en roca, alusivos a la transmisión del mensaje, existentes hoy en el Museo Etnológico de Hamburgo; la presencia de dibujos referidos a la fonación, encontrados en el trono del faraón egipcio, Sesostris; la existencia de dibujos del antiguo arte peruano relacionados con intervenciones quirúrgicas para mejoras foniátricas; inscripciones aborígenes de pictogramas, que insinúan una posible e incipiente interpretación de la oscilación sonora (voz), encontradas en México, la India y África occidental; referencias en la Biblia sobre fonación; referencias brahamánicas sobre tipos de respiración; explicaciones sobre el origen mítico de la voz en pueblos de la antigüedad, etc. Estos y otros documentos, hacen pensar con inquietud y admiración, en los intereses que estas civilizaciones, y seguramente otras, tuvieron, mostraron y dejaron sobre el proceso fónico humano.

En forma más sistemática, posteriormente (s. IV a C.), la cultura hindú, con Panini a la cabeza, nos dejó clasificaciones vocálicas y consonánticas, aún no desvirtuadas: Sócrates, Platón, Aristóteles, Hipias, ... disertaron también sobre el fenómento fónico, y con diferentes criterios en la época del florecimiento griego; Hipócrates y Galeno dejaron también sabias investigaciones sobre la voz; Quintiliano, retórico español acogido con notable interés por las cortes imperiales romanas, nos dejó en sus Instituciones Oratorias un sesudo tratado de fonética, con recomendaciones para el buen decir. Bordeando la Edad Media, Leonardo Da Vinci estudió gráficamente la pronunciación de la voz humana; con Juan de Valdés y Antonio de Nebrija (españoles), en obras como Dialogo de la lengua y Reglas de la Orthographia en la lengua castellana, respectivamente, la fonética toma una dimensión importante en el mundo hispánico. Aparecen luego, intentos serios y progresivos de transcribir fonéticamente (mediante el uso de signos convencionales) situaciones de lengua y habla a fin de facilitar la mejor interpretación y pronunciación del fenómeno fónico; nos referimos aquí a las escrituras fonéticas desarrolladas entre 1541 y 1888, años en que se establece definitivamente el Alfabeto Fonético Internacional (denominado AFI o APHI). En este proyecto contribuyeron, sucesivamente, desde 1541, John Hart, Robert Robinson, John Wilkins, William Holder, Smith y Mulcaster, Isaac Pitman, Ellis, Lepsius, Bell, hasta la aparición notabilísima del francés Paul Passy y el inglés Henry Sweet, a finales del siglo XIX, quienes a través de la Asociación de Profesores de Lenguas vivas (de la cual fue miembro el bogotano Rufino José Cuervo, recién llegado a París en 1882) consolidaron el Intemational Phonetic Alphabet, hoy vigente.

Pero el desarrollo de estas ciencias no se detiene; agreguemos que el interés por los campos fonéticos estimuló también a otros científicos, no propiamente lingüistas, sino 
entendidos en otras disciplinas, para corroborar lo dicho por Jones. Muchos de los instrumentos de medición fonética y algunas concepciones, más físicas y matemáticas que lingüísticas, fueron creación de técnicos, fisiólogos, médicos, ingenieros, físicos, según referimos a continuación.

Fourier, físico francés, integró la onda compleja en 1822; Gentili, italiano, elaboró el glosógrafo en 1822; Babington, inglés, inventó el laringoscopio en 1829; Muller, médico alemán, creo la laringe artificial en 1887; Ludwig, técnico alemán, ideó el quimógrafo en 1847; Czermak, fisiólogo checo, se ocupó de la laringoscopia clínica en 1858; Helmholtz, físico alemán, descubrió la teoría de la resonancia vocálica en 1863, Brücke, fisiólogo alemán, diseñó el labiógrafo en 1871; Helkwag, fisiólogo alemán, ideó el triángulo vocálico en 1781; en 1878 el norteamericano Edison construyó el fonógrafo; Lenz, filólogo alemán, fabrica el palatógrafo en 1887; los laboratorios Bell de New York, inventaron el espectrógrafo en 1946; Larcerda, acusticista portugués, concibe el cromógrafo (fecha sin confirmar); y podríamos agregar a esta lista, muchos otros más, autores de teorías, aparatos, modelos, etc.

\section{Otros personajes y eventos del ámbito universal de la fonética}

A los nombres ya mencionados, y en recuento rápido, podríamos recordar otras contribuciones a nivel fonético-fonológico: al griego Hipias (por su estudio de la naturaleza sonora de letras y silabas), a Jakob Grimm, por su Ley de mutación consonantica, a August Schleicher, por su Manual del lituano, a Rousselot, padre de la fonética experimental, a Edward Sievers por su obra Zur Akzent der Germanische, a Paul Menzerath por su Die Phonetische Structur, a Carl Meinhof por su gran Introduction to the Phonology of Bantu y por sus estudios de las lenguas africanas, a Bertil Malmberg, Gerold Ungeheuer (q.e.p.d.) y Antonio Quilis, afamadísimos fonetistas europeos (sueco, alemán y español), visitantes del Instituto Caro y Cuervo en 1964, 1971,1977, respectivamente, a Kenneth Pike, presidente del ILV, a Peter Ladefoged, el más prestigioso acusticista y fonetista actual, a Dwight Bolinger, estudioso del español por su Intensive Spanish, a Ferdinand de Saussure por su teoría sobre Langue et parole, a Vilém Mathesius, primer presidente del Círculo Lingüístico de Praga, a André Martinet, creador del funcionalismo, a Roman Jakobson, del binarismo, a Edward Sapir, autor de The Language, a Leonard Bloomfield, por su Language, a Noam Chomsky y Morris Halle, notabilísimos generativistas, a Andrés Bello y sus tratados sobre Principios de Ortología y Métrica, a Tomás Navarro, Manuel Alvar, Amado Alonso y Emilio Alarcos (españoles), Gilliéron, padre de la dialectología, George Straka y Bohuslav Hala, afamados fonólogos checos, y por lo menos a cien nombres más que deberían completar esta galería.

Especial mención hacemos aquí de los inventores del sonógrafo (U.S.A., 1946), indispensable e insustituible aparato actual, asequible ya en versiones digitales y computarizadas, útil para la comprobación acústica experimental de fenómenos de lenguas nuevas, de las cuales no es aconsejable ratificar impresionísticamente situaciones fonéticas, sin que antes sean llevadas ellas a examen y medición exhaustivos, merced a los medios experimentales acústicos, como el sonógrafo, entre otros. A este se agregaría el concurso de 
Visipitch, nasógrafo, electropalatógrafo, laringógrafo, aerófono, etc. y modernos métodos como la cinemaradiografia. Sólo así podremos estar en capacidad de negar o afirmar con precisión lo que impresionísticamente nuestro deficiente oído, sólo intuye o sospecha. Modernamente, los espectrogramas son también utilizados para análisis de voz, con propósitos jurídicos, en la aportación de pruebas legales para identificación de voces, a nivel criminalístico. Veamos, detenidamente, una muestra espectrográfica (visible speech):

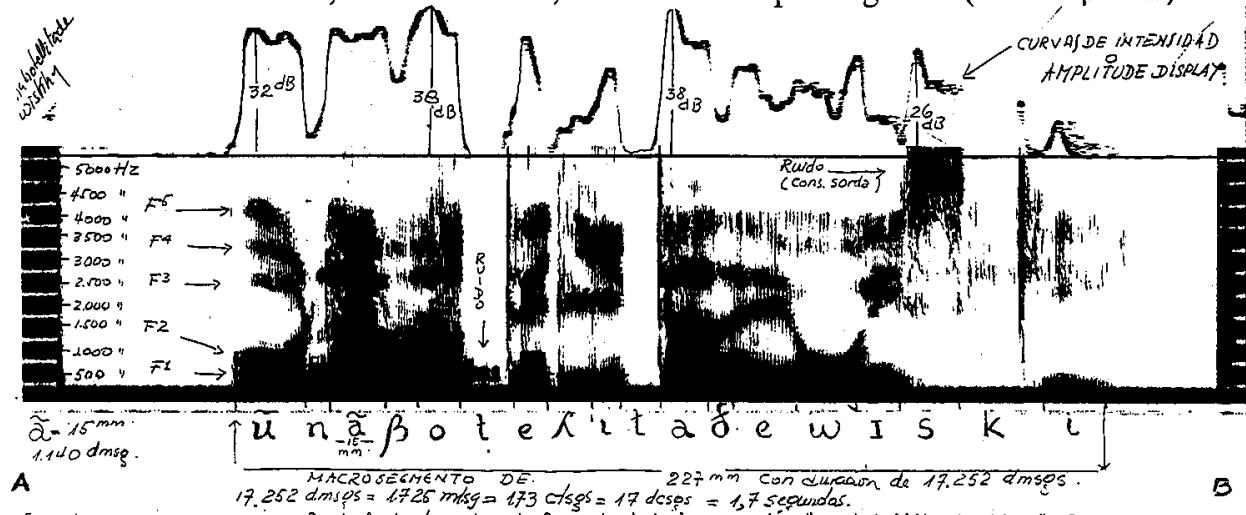

Espectrograma o sonograma en Banda Ancha (muestra de formantes) de la expresion "una botellfta de uhisky". Pueden observarse los diferentes formentes $\left(F_{1}, F_{2}, F_{3}, \ldots\right)$ en los registros acústicos, correspondientes a vocales y consonantes sone ras $[n, \beta, \mathcal{\beta}, \delta]$. Las consonantes sordas $[t, 8, k]$ no poseen formantes. Arriba, la curva de intensidad, útil para le medición de intensidades en decibeles, con propósitos acentuales. A izquierda y derecha, la escala de frecuencia, estimable en hertzios, necesarios pera estudiar entonación, agudeza y gravedad de sonidos. El timbre [ä, ũ] (nasalizadas), [u] semiconsonante, [I] abierta, se aneliza con las pRansiciones ascendentes o descendentes de determinados formantes on cada microsegmento. Finalmente, los estinativos de duración se calculan multipifeando la duración en mm por $76 \mathrm{dmsg}$ : $15 \times 76$ = 1140 dmsg. Un sonograma como éste utiliza papal "teledeltos" (elactrocarbonado magnéticamente) con un espacio útil de 31,5 $\mathrm{cm}, A-B$ en un tiempo máximo de 2,4 segundos. El aparato utilizado es el espectrágrafo "Kay elemetrics" (visible speech) modelo 60618 .

\section{Ingreso de la fonética y la fonología en el panorama de las ciencias}

Hay un acontecimiento que marca el punto de partida para esta apreciación: en 1786 el diplomático inglés William Jones, residente en la India, pronuncia un discurso en la sede en la Sociedad Asiatica de Calcuta y advierte en él, que a su parecer, existe una lengua madre o tronco, el hindú, que guarda muy estrecha relación con lenguas europeas, como el latín, griego, inglés y alemán..., lo cual le hace intuir una afinidad y relación - en planos fonéticos - entre todas ellas.

Pero es en 1816-18 cuando, tanto el danés Rasmus Rask, como el alemán Franz Bopp, aseguran en sus profundos estudios que, descubierto el sánscrito (hindú), pudieron comprobar su influencia como lengua inflectiva sobre las lenguas inflectivas indoeuropeas, entre ellas las de las familias helénica, itálica, báltica, eslava, germánica, céltica a más del iraniano, el tocario y el hitita. Estas influencias y dependencias se mostraron y se probaron, mediante examen de los elementos fonéticos y morfológicos observados y presentes en la transición de unas lenguas a otras, de las aquí mencionadas; esta progresión puede presentar este orden: sánscrito > griego > latín > lenguas romances (español, italiano, francés, portugués, rumano, catalán, provenzal, dalmático, rético, y sardo). Estos eventos comparativos proporcionaron la consolidación y desarrollo de la fonética como ciencia y como disciplina básica e insustituible en los estudios lingüísticos; tal orientación científica (comparatismo) entró así a desplazar y a superar inmediatamente los exámenes filológicos, único medio, conocido hasta entonces, para el estudio de las lenguas por examinar. 
Curiosa y coincidencialmente, con la probada tradición y prestigio que ha tenido Colombia en Latinoamérica, como país donde la fonética echó viejas raíces, aparecen desde la colonia, trabajos de investigación fonética dirigidos al estudio de las lenguas de nuestros aborígenes, especialmente el chibcha. Son dignos de mención las observaciones de Fray Jerónimo de San Miguel sobre lengua mosca; las reflexiones de Fray Bernardo de Lugo acerca de la pronunciación indígena; las voces y pronunciación del chibcha de Lucas Fernández de Piedrahita; los estudios de pronunciación y sílabas, referidas al guahibo, del Padre José Gumilla; pero estos no son los únicos aportes acerca del examen fonético que en la colonia se hicieran sobre lenguas indígenas; podrían enumerarse aún más. Pero quien realmente inaugura estudios fonéticos de precisión en Colombia es el sabio bogotano Ezequiel Uricoechea y Rodríguez; en 1872 publica él, en Madrid, El alfabeto fonético de la lengua castellana, primer estudio de este género en el mundo hispánico, y atinado acierto sobre la descripción fonética de la lengua española. Con él, se anticipó meritoriamente 43 años a lo que fuera el alfabeto ARFE, ideado y difundido por Tomás Navarro en 1915 en la Revista de Filología Española (Madrid).

Fue Uricoechea, además, médico graduado en Yale a los 18 años, y doctor diplomado en filosofía con especialidad en química y mineralogía, en la Universidad de Göttingen, a los 20. Aquí en Bogotá, y muy joven aún, antes de partir al Viejo Mundo, de donde no regresaría, había sido dedicado consejero de Rufino José Cuervo, en sus tareas de árabe, de sánscrito y de alemán. Radicado ya en Bélgica (1878), fue nombrado titular de la primera cátedra de árabe, organizada por la Universidad Libre de Bruselas; este galardón, ganado por oposición, fue entregado incondicionalmente al bogotano.

En junio de 1965, su antigua universidad belga reconoce, públicamente, los méritos excelsos de Uricoechea, y en acto especial (gestión que no ha hecho Colombia), con asistencia de altas personalidades belgas, españolas, árabes y colombianas, este centro europeo de estudios inauguró en tal fecha la biblioteca de árabe Ezequiel Uricoechea y se descubrió el retrato al óleo del santafereño, enviado desde Bogotá para tal ocasión; todo como sentido homenaje belga a quien fuera el primer profesor de lengua árabe en esa importante casa universitaria. Es orgullo nacional haber tenido un embajador mundial en la persona de don Ezequiel, quien murió en Beirut (1880); lo sorprendió la muerte cuando, precisamente, estudiaba apasionadamente fonética dialectal árabe, en tal inhóspitas tierras. De otra parte, la figura de Rufino José Cuervo se erige también como notable fonetista a través de las páginas de sus obras Apuntaciones críticas sobre el lenguaje bogotano, de que tanto necesitan nuestros alumnos y profesores; Castellano popular y castellano literario, Disquisiciones sobre filologia castellana, filologia clasica y crítica literaria, todas plenas de información fonética; dignos de mención son los soberbios intercambios epistolares sobre los mismos temas, entre Cuervo y varios sabios europeos como Friedrich Pott, Menéndez Pidal, Hugo Schuchardt, Isaia Ascoli, Emilio Teza, Cejador y Frauca, Rudolph Lenz, Morf, Baist, Meyer Lübke y el mexicano Rafael Angel de la Peña, entre otros, recopilados en los Epistolarios que publica el Instituto Caro y Cuervo. 
El contradiálogo de la lengua de Miguel Antonio Caro es otro peldaño de la fonética en Colombia. El acento de José Tomás Eastman, ya más reciente, es también de merecimiento. A partir de los años 50, Luis Flórez, de Armero (Tolima), como discípulo que fuera de Tomás Navarro, inaugura los estudios dialectales sistemáticos en Colombia, mediante el examen del habla de la población municipal del país, también en sus maneras fónicas; buenas enseñanzas de fonética se hallan, además, en sus obras Temas de castellano, Apuntes de español y Lecciones de pronunciación; su gran contribución es el ALEC (Atlas Lingǘstico y Etnográfico de Colombia), en 6 tomos, de reconocido prestigio internacional. Dos de ellos están dedicados al estudio de la fonética regional. Actualmente el dialectólogo J. Joaquín Montes prosigue los estudios derivados del Atlas Lingüístico y Etnográfico de Colombia con novedoso éxito. Finalmente, la existencia del único laboratorio de fonética experimental del país, en el Instituto Caro y Cuervo, representa punto moderno de avanzada para estudios acústicos de lenguas; especial interés manifiesta el Instituto en el estudio de la lengua española y de las lenguas indígenas, a base de ayudas instrumentales y experimentales. Seguramente la Universidad Distrital de Bogotá se apuntará otro gran logro, al cristalizar el proyectado Laboratorio de Lenguạs y de Fonética experimental dotados con modernísimos aparatos, sección ya en marcha, organizada por el Departamento de Filología e Idiomas de esta casa universitaria.

Bibliografía.

Kaiser, L., Manual of Phonetics, Amsterdam, North Holland Publishing Co., 1957.

Mounin, G., Histoire de la Linguistique, París, P.U., 1967.

Pancocelli-Calzia, Giulio, 3000 Jahre Stimmforschung, Marburg, N. G. Elwert Verlag, 1961.

Allen, W. S., Phonetics in Ancient India, London, Oxford University Press, 1953.

Rosenkranz, Bernhard, Der Ursprung der Sprache, Heidelberg, Carl Winter, Universitätverlag, 1961.

Leroy, Maurice, Las grandes corrientes de la Lingǘstica, México, F. C. E., 1969.

Todorov - Ducrot, Tzvetan, Diccionario enciclopédico de las ciencias del lenguaje, México, Siglo XXI Editores, 1974.

Grammont, Maurice, Traite de Phonétique, París, Libraire de la Grave, 1971.

Lewandosky, Theodor, Diccionario de lingüísica, Madrid, Ediciones Cátedra, 1982.

Lázaro C., Fernando, Diccionario de términos filológicos, Madrid, Editorial Gredos, 1962. 


\section{Povzetek}

\section{TRADICIJA IN SODOBNOST GLASOSLOVJA: FONETIKA IN FONOLOGIJA}

V prvem delu svojega članka A. Calderón Rivera piše o glasoslovju, o tem, kaj fonetika in fonologija pomenita, katera področja pokrivata, kakšen je njun pomen in njun zgodovinski razvoj $v$ svetovnem merilu. Avtor omenja vsa pomembnejša imena znanstvenikov, ki so $\mathrm{z}$ raznih vidikov pripomogli $\mathrm{k}$ razvoju fonetike in fonologije. $\mathrm{V}$ zadnjem delu se posveti razvoju glasoslovnih znanosti v Kolumbiji, omenja pomembne kolumbijske raziskovalce, kot so Ezequiel Uricoechea y Rodríguez, Rufino José Cuervo, Miguel Antonio Caro, in opisuje današnje stanje raziskav na področju fonetike in fonologije v Kolumbiji. 